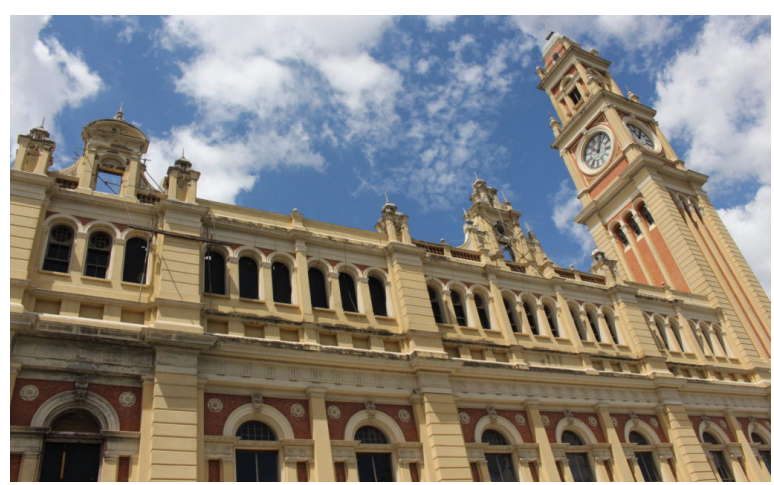

\title{
Do edifício ao território: o patrimônio urbano industrial na trajetória do CONDEPHAAT (1968-2018)
}

\author{
From buillding to territory: the urban industrial heritage in the trajectory \\ of the CONDEPHAAT (1968-2018)
}

Manoela Rossinetti Rufinoni*

*Professora do Departamento de História da Arte e do Programa de Pós-Graduação em História da Arte da Escola de Filosofia, Letras e Ciências Humanas da Universidade Federal de São
Paulo (EFLCH-UNIFESP) Autora do livro Preservação e Restauro Urbano: intervenções em sítios históricos industriais. São Paulo: Fap-Unifesp, Edusp, Fapesp, 2013.

\section{Resumo}

A amplitude do conceito de patrimônio industrial, ratificada pela Carta de Nizhny Tagil (2003) e pelos Princípios de Dublin (2011), evidencia a dimensão urbana e territorial dos testemunhos da industrialização como um dos principais desafios a serem enfrentados pelas ações de preservação. Ao analisar uma seleção de processos de tombamento do CONDEPHAAT (Conselho de Defesa do Patrimônio Histórico, Arqueológico, Artístico e Turístico do Estado de São Paulo, órgão criado em 1968), identificamos, desde meados da década de 1970, uma paulatina percepção dessa dimensão urbana nos estudos voltados à preservação do patrimônio industrial, não obstante as dificuldades relacionadas aos limites do instrumento de tombamento, pensado originalmente para a tutela de edifícios considerados isoladamente. A partir da análise de uma seleção de processos de tombamento de bens industriais paulistas, este artigo pretende destacar a presença e a amplitude das menções à questão urbana e territorial ao longo da trajetória do CONDEPHAAT, evidenciando as formas de entendimento das relações urbanas inerentes ao patrimônio industrial em cada período histórico e as possibilidades de aprofundamento desse debate na atualidade.

Palavras-chave: Patrimônio Urbano; Políticas de Preservação, São Paulo (Estado)

\section{Abstract}

The breadth of the concept of industrial heritage, ratified by the Nizhny Tagil Charter (2003) and the Dublin Principles (2011), highlights the urban and territorial dimension of the testimonies of industrialization as one of the main challenges to be faced by preservation actions. By analyzing a selection of administrative legal processes of the CONDEPHAAT (Council of Defense of the Historical, Archaeological, Artistic and Tourist Heritage of the State of São Paulo, an organ created in 1968), we identified, since the mid-1970s, a gradual perception of this urban dimension in studies focused on the preservation of industrial heritage, despite the difficulties related to the limits of the instrument called "tombamento", originally intended for the protection of buildings considered in isolation. From the analysis of some administrative legal process of preservation of São Paulo industrial heritage, this article intends to underscore the presence and breadth of mentions to the urban and territorial issue along the CONDEPHAAT trajectory, highlighting the ways of understanding the urban relations inherent to this heritage in each historical period and the possibilities for deepening this debate today.

Keywords: Industrial heritage, Cultural heritage preservation policies, São Paulo (State). 


\section{Introdução}

A amplitude do conceito de patrimônio industrial, referendada pela Carta de Nizhny Tagil (2003) e pelos Princípios de Dublin (2011), evidencia a dimensão urbana e territorial dos testemunhos da industrialização como um dos principais desafios a serem enfrentados pelas ações de tutela ${ }^{1}$. A questão não diz respeito apenas à interferência física de grandes estruturas em uma dada localidade, impulsionando processos de urbanização ou transformando paisagens preexistentes a partir da ocupação de áreas extensas. Além dessa dimensão material, geralmente de apreensão mais imediata, devemos considerar as ações, fluxos e formas de uso da cidade desencadeadas pela presença da atividade fabril. Aspectos, por vezes, ainda identificáveis na malha urbana, mesmo após a desativação da produção, com base na observação atenta das estruturas remanescentes e das memórias e representações construídas a partir desse legado, na cidade de hoje.
A definição de patrimônio industrial exposta em documentos internacionais, como a Carta de Nizhny Tagil (TICCIH, 2003) e os Princípios de Dublin (ICOMOS, TICCIH, 2011), corrobora essa dimensão de análise. Na Carta de Nizhny Tagil, define-se o patrimônio da industrialização como "os vestígios da cultura industrial que possuem valor histórico, tecnológico, social, arquitetônico ou científico", abarcando estruturas e infraestruturas destinadas às atividades de produção, como "edifícios e maquinaria, oficinas, fábricas, minas e locais de processamento e de refinação, entrepostos e armazéns, centros de produção, transmissão e utilização de energia, meios de transporte" e, também, equipamentos relacionados à vida cotidiana dos operários e da comunidade do entorno, "como os locais onde se desenvolveram atividades sociais relacionadas com a indústria, tais como habitações, locais de culto ou de educação." As diretrizes do documento se estendem, ainda, à documentação relativa ao 
patrimônio industrial e "aos registos intangíveis contidos na memória dos homens e das suas tradições". Em documento mais recente, nos Princípios de Dublin, notamos uma ampliação considerável dessa definição, incorporando as dimensões intangíveis da industrialização de forma mais direta. Desse modo, além dos testemunhos materiais das atividades fabris, o conceito passa a incluir "os saberes e fazeres técnicos, a organização do trabalho e dos trabalhadores, ou um complexo legado de práticas sociais e culturais resultantes da influência da indústria na vida das comunidades, as quais provocaram decisivas mudanças organizacionais em sociedades inteiras e no mundo em geral."

Em ambas as definições, há certa ênfase nas estruturas construídas, na arquitetura e na técnica; porém, tais aspectos são entendidos como suportes de relações socioculturais e memoriais relacionadas ao mundo do trabalho, evidenciando que os valores patrimoniais dos testemunhos da industrialização podem se manifestar em variadas dimensões, materiais e imateriais. De um lado, considerando a repercussão no entorno imediato, a instalação de uma indústria atrai trabalhadores, impulsiona a construção de residências e o surgimento de estabelecimentos comerciais e equipamentos voltados ao lazer, educação, culto; ou seja, alimenta novas funções, fluxos, cotidianidades e memórias urbanas. De outro lado, no interior do universo da produção, os sítios fabris promovem intrincadas conexões funcionais entre edifícios e equipamentos em diferentes níveis, a exemplo das estruturas voltadas ao abastecimento de água e energia ou, ainda, daquelas associadas ao atendimento logístico, como os ramais ferroviários para recebimento de matérias-primas ou escoamento da produção, em uma rede de conexões que pode alcançar dimensões territoriais. Muitas vezes, portanto, o edifício fabril considerado isoladamente é apenas uma pequena engrenagem de um complexo sistema, talvez incompreensível se não buscarmos evidenciar outros elementos que nos permitam ler, na cidade de hoje, a dinâmica urbana e antropológica associada à produção e ao trabalho, assim como as representações e memórias construídas em torno desse sistema ao longo do tempo, articulando o passado e o presente na cidade contemporânea. Os estudos voltados à valorização e tutela do patrimônio da industrialização, portanto, devem atentar para essa complexidade.

Os sítios industriais - sejam espaços voltados à fabricação propriamente dita, sejam sítios relacionados aos sistemas de transporte, a exemplo das estruturas ferroviárias -, possuem uma composição espacial intimamente relacionada ao desenvolvimento das atividades produtivas e das relações de trabalho ali sediadas. Esses sítios agrupam diversos edifícios e espaços de produção - muitas vezes edificados em diferentes épocas e com tipologias construtivas distintas -, que nos permitem entender a expansão da indústria, 
a adoção de novas tecnologias e a repercussão de sua presença na malha urbana envoltória. Eventualmente, uma única edificação industrial isolada pode representar valores excepcionais, mas em muitos casos trata-se de uma rede de edifícios, industriais ou não, inter-relacionados em torno da produção: galpões, edifícios fabris, vilas operárias, pátios de manobras, equipamentos, estruturas voltadas ao fornecimento de água e energia etc. (RUFINONI, 2013, p.192). Conforme acenamos, o entorno desses sítios - áreas voltadas a outras funções, a exemplo do uso residencial -, deve também ser verificado com atenção, pois geralmente é composto por parcelas urbanas formadas e consolidadas em grande parte devido à presença da indústria, são conjuntos construídos que mantêm a homogeneidade volumétrica e a horizontalidade responsáveis pela configuração da paisagem e da tradição urbana de muitos bairros industriais. Antonio Parisella (2000, p.52), ao comentar sobre as particularidades da configuração espacial, construtiva e histórica dos edifícios industriais, ressalta uma dupla exigência para a avaliação dessas estruturas como patrimônio cultural e para as ações de tutela e reconversão de uso:

A primeira [exigência] diz respeito ao edifício individualmente e às relações diretas e específicas entre o seu uso (significado) original e o uso (significado) que deveria / poderia assumir. [...] A segunda exigência diz respeito à compreensão do duplo sistema de relações que o edifício assumia, horizontalmente, dentro do espaço urbano organizado onde se situava (bairro, zona) e, verticalmente, dentro do setor produtivo do qual fazia parte.

Com base nessa diretriz, evidenciamos a necessidade de analisar com atenção as características formais e socioculturais dos bairros ocupados ou influenciados pela atividade industrial, a exemplo do parcelamento do solo e das tipologias construtivas, funções e usos predominantes em cada localidade. Em muitos casos, podemos notar um ordenamento espacial específico para o atendimento de funções produtivas que repercute em toda a composição do conjunto, seja na distribuição dos edifícios fabris, seja na localização de vilas operárias e outros equipamentos urbanos do entorno. A importância e a relevância cultural dos sítios industriais estão diretamente relacionadas à apreensão dessas especificidades, ao entendimento das qualidades materiais, espaciais, sociais, memoriais, que concorrem para a configuração desse cenário. Conforme afirmou Meneguello (2012, p.82-83), "estes bens relacionam-se entre si em complexas redes interligadas (como as ferrovias e todos os bens a ela associados) e sua salvaguarda isolada é insuficiente para a compreensão da rede de recebimento de matéria-prima, produção e escoamento que definem a atividade industrial".

A compreensão dessa complexidade espacial tem sido apontada como uma das principais dificuldades a serem enfrentadas pelas ações de 
2. Lei Estadual 10.247 de 22 de outubro de 1968. Dispõe sobre a competência, organização e o funcionamento do Conselho de Defesa do Patrimônio Histórico, Artístico e Turístico do Estado, criado pelo artigo 123 da Constituição Estadual e dá outras providências.

3. Citamos, neste sentido, a Carta de Veneza (1964) e a Declaração de Amsterdã (1975),entre outros. O documento de Amsterdã propõe a chamada "conservação integrada", método de atuação que conclama a participação multi e interdisciplinar no campo da preservação, bem como a integração entre as iniciativas de tutela e as práticas e normativas advindas do planejamento urbano e territorial (CURY, 2000; RUFINONI, 2013, p.135-165)

4. Programa de Preservação do Patrimônio Ambiental Urbano. Centro de Documentação do CONDEPHAAT, 1976 (mimeo), Processo n.20.025/76, Seção de Protocolo do CONDEPHAAT. preservação do patrimônio industrial. E esta não é uma preocupação recente. A questão foi exposta por Ulpiano Bezerra de Meneses (1988, p.68-73), na década de 1980, durante o $1^{\circ} \mathrm{Se}-$ minário Nacional de História e Energia, quando ressaltou a importância das formas de composição do espaço na análise de complexos industriais. Segundo o autor, nenhuma amostragem de "estruturas significativas" de um complexo industrial - elementos apartados do todo -, seria capaz de representar seu caráter documental e, principalmente, formal e estético. E a corrupção dessa dimensão espacial, além de comprometer o entendimento histórico de todo o metabolismo da atividade produtiva, deturparia composições formais únicas, desconsiderando por completo qualquer atributo estético possível. Para o autor, portanto, estruturas industriais preservadas isoladamente seriam apenas meras "carcaças simbólicas".

Na trajetória do Conselho de Defesa do Patrimônio Histórico, Arqueológico, Artístico e Turístico (CONDEPHAAT) - órgão criado em 1968, subordinado à Secretaria da Cultura do Estado de São $\mathrm{Paulo}^{2}$, e voltado à identificação, proteção e preservação de bens móveis e imóveis do patrimônio cultural e ambiental do Estado de São Paulo -, observamos uma paulatina percepção dessa complexidade nos estudos voltados à preservação de bens industriais, notadamente a partir do final da década de 1970, não obstante as dificuldades relacionadas aos limites do próprio instru- mento de tombamento, pensado originalmente para a tutela de edifícios considerados individualmente. A historiografia sobre a atuação do órgão aponta para uma gradativa abertura conceitual nos estudos de preservação a partir dessa data, seja nas discussões em torno de novos objetos de proteção, buscando considerar o patrimônio como um fato cultural em que o homem é o alvo principal das ações preservacionistas; seja na atenção ao meio ambiente construído, procurando compreendê-lo como fato cultural e como espaço e lugar das relações sociais.

O delineamento de ideias preservacionistas pautadas por um entendimento mais amplo do conceito de patrimônio, incorporando suas dimensões cultural, ambiental e urbana ${ }^{3}$, acompanhou as discussões em pauta no cenário internacional, observadas, sobretudo, desde o final da década de 1960. Tal postura coincidiu, conforme esclareceu Rodrigues (2000, p.79-80), com a emergência de demandas da própria sociedade neste debate, quando a questão da preservação do patrimônio adquiriu força como direito social.

$\mathrm{Na}$ atuação do CONDEPHATT, nesse período, a discussão em torno da ideia de "patrimônio ambiental urbano" - conceito que abarcaria, além da materialidade construída, os "aspectos socioculturais que impregnam todas as edificações, mesmo as de caráter recente" (apud RODRIGUES, 2000 , p.61) ${ }^{4}$, sinalizou um momento de amadurecimento desse debate, ainda que os meios 
5. SÃO PAULO (Estado). Secretaria de Negócios Metropolitanos, Emplasa. Comunidade em debate: patrimônio ambiental urbano. São Paulo, 1979.

6. Salientamos que a breve análise de processos de tombamento, exposta neste artigo, não se pretende exaustiva ou conclusiva. A seleção de bens pautou-se pela recorrência de menções à questão urbana e territorial nos autos dos processos. legais para a tutela patrimonial permanecessem vinculados, essencialmente, ao tombamento.

As discussões sobre o conceito de patrimônio ambiental urbano surgiram no âmbito do planejamento metropolitano, em órgãos de gestão urbana da Prefeitura Municipal de São Paulo e com o envolvimento de diferentes profissionais, sobretudo, atuantes na área da preservação (RODRIGUES e TOURINHO, 2016, p.80). Potencialmente, tais debates abriam caminho para a preservação de ambientes da cidade em sintonia com as ações de planejamento urbano e territorial, interpretando tais espaços em uma perspectiva mais ampla, atenta à sua constituição sociocultural, memorial e simbólica; e conferindo um caráter público à prática preservacionista, ao considerar os edifícios tutelados no presente e no cotidiano dos cidadãos (RODRIGUES, 2000, p.66).

Em linhas gerais, na asserção de Ulpiano Bezerra de Meneses, um dos profissionais mais atuantes neste debate, o patrimônio ambiental urbano seria definido como "um sistema de objetos socialmente apropriados, percebidos como capazes de alimentar representações do ambiente urbano" (apud RODRIGUES, 2000, p.66)5. Meneses deposita sua atenção, portanto, nas relações que se estabelecem entre artefatos e sujeitos, e não no edifício isolado, conferindo protagonismo ao reconhecimento da apropriação social do espaço como etapa decisiva na atribuição de valores às materialidades, então entendidas como "suportes de significados" e não como "carcaças simbólicas". Identificamos, portanto, elementos comuns entre os argumentos de Meneses em torno do conceito de patrimônio ambiental urbano, na década de 1970, e aqueles que seriam mobilizados pelo autor anos depois, em suas reflexões sobre a preservação do patrimônio industrial, como vimos. Não por acaso, portanto, as particularidades sistêmicas do patrimônio da industrialização têm nos lançado, ontem e hoje, ao debate sobre a amplitude do conceito de patrimônio edificado e sobre os mecanismos necessários para tutelá-lo, considerando a relação com o ambiente urbano e a apropriação sociocultural do espaço, do edifício ao território.

$\mathrm{Na}$ análise de processos de tombamento de alguns bens industriais protegidos pelo CONDEPHAAT, notamos a menção à questão urbana e territorial em diversos pareceres, atribuindo importância ao bem ora devido ao seu papel na indução da urbanização do entorno, ora devido à sua inserção na paisagem e à promoção de particulares cotidianidades urbanas ${ }^{6}$. Tais preocupações, contudo, não chegaram a oferecer instrumentos efetivos que viabilizassem a preservação nesta dimensão mais ampla. Sem pretender análises conclusivas, comentaremos, a seguir, alguns processos em que a dimensão urbana e territorial do patrimônio industrial chegou a ser mobilizada por técnicos e conselheiros em seus argumentos em defesa da tutela. Em nossa 
7. Como resultado dessa metodologia, foram tombados dezenas de conjuntos e complexos ferroviários, localizados nas cidades de: Franco da Rocha, Jaraguá, Rio Grande da Serra, Várzea Paulista, Caieiras, Perus, Ribeirão Pires e Jundiaí (tombados em 2011), e Santos (2018), no trajeto da São Paulo Railway; Vinhedo e Louveira (2012), Valinhos, Piratininga e Sumaré (2013), no trajeto da Cia Paulista de Estradas de Ferro; Andradina e Araçatuba (2012), no trajeto da Estrada de Ferro Noroeste do Brasil; Botucatu (2012), Piraju (2013), Chavantes e Avaré (2016), Sorocaba e Ourinhos (2018), no trajeto da Estrada de Ferro Sorocabana; Piquete (2014) e Cruzeiro (2015), no trajeto da Estrada de Ferro Central do Brasil; Pindamonhangaba (2017), no entroncamento entre as Estradas de Ferro Central do Brasil e Campos do Jordão; Jaguariúna (2016) e Águas da Prata (2018), no trajeto da Companhia Mogiana de Estradas de Ferro; e Caetetuba (2018), no trajeto da Estrada de Ferro Bragantina Salientamos, ainda, o tombamento do conjunto de residências e depósito de locomotivas da Rede Ferroviária Federal (RFFSA), em Araçatuba (2012). análise, tais processos foram tomados, por um lado, como documentos administrativos que evidenciam metodologias e critérios adotados pelo órgão de preservação; e, por outro, como fontes históricas que nos auxiliam a compreender as questões envolvidas na atribuição de valores a determinados bens edificados, assim como na respectiva construção de narrativas patrimoniais.

No caso dos bens ferroviários, frequentemente, associa-se a valorização desse patrimônio à sua relação com o desenvolvimento e crescimento das cidades, além do vínculo imediato, físico e simbólico, com a questão da mobilidade, com a alusão às chegadas e partidas, e abertura de novos caminhos, em nível urbano e regional. $A$ observação atenta da caracterização urbana e territorial desses bens, contudo, intensificou-se significativamente a partir da década de 2010, a partir do levantamento intitulado "Patrimônio Ferroviário: linhas e estações ferroviárias do Estado de São Paulo", elaborado pelo Grupo de Estudos de Inventário da Unidade de Preservação do Patrimônio Histórico (GEl/UPPH). Esse estudo tem subsidiado ações de preservação voltadas a complexos ferroviários entendidos em sua complexidade funcional, em sua relação com o organismo urbano envoltório e com a realidade regional que ajudou a compor e consolidar. Em algumas regiões, a área de domínio de uma li- nha férrea chegou a atingir dimensões territoriais, condicionando referenciais geográficos, conexões entre cidades e práticas socioculturais em diferentes níveis. A questão é apontada por Martins, Cardoso e Andrade (2012, p.52):

Essas rotas (estradas de ferro) não só qualificaram a comunicação potencializando a economia mas engendraram regiões culturalmente homogêneas, definidas por sociedades com características próprias. De certa forma, padronizaram nas respectivas regiões, modelos de cidades, partidos arquitetônicos específicos, práticas culturais e unidades linguísticas que vincaram as respectivas paisagens e as sociedades ali constituídas. [...] "Sou do Vale", "nasci na Paulista", "venho da Mogiana", "vivi na Sorocabana", são expressões até hoje consagradas por seus moradores, alusivas a estágios econômicos e redes de cidades com identidades próprias e denominadores comuns.

Diferentemente dos critérios de seleção anteriores, como veremos a seguir, os tombamentos mais recentes de bens relacionados às estradas de ferro têm atentado para o caráter de conjunto das instalações ferroviárias, preservando estações e anexos, quando existentes, e denominando os bens como Conjuntos ou Complexos Ferroviários, atitude que evidencia a compreensão da importância patrimonial das relações entre as várias unidades construídas num mesmo conjunto, característica fundamental do patrimônio industrial e ferroviário. 


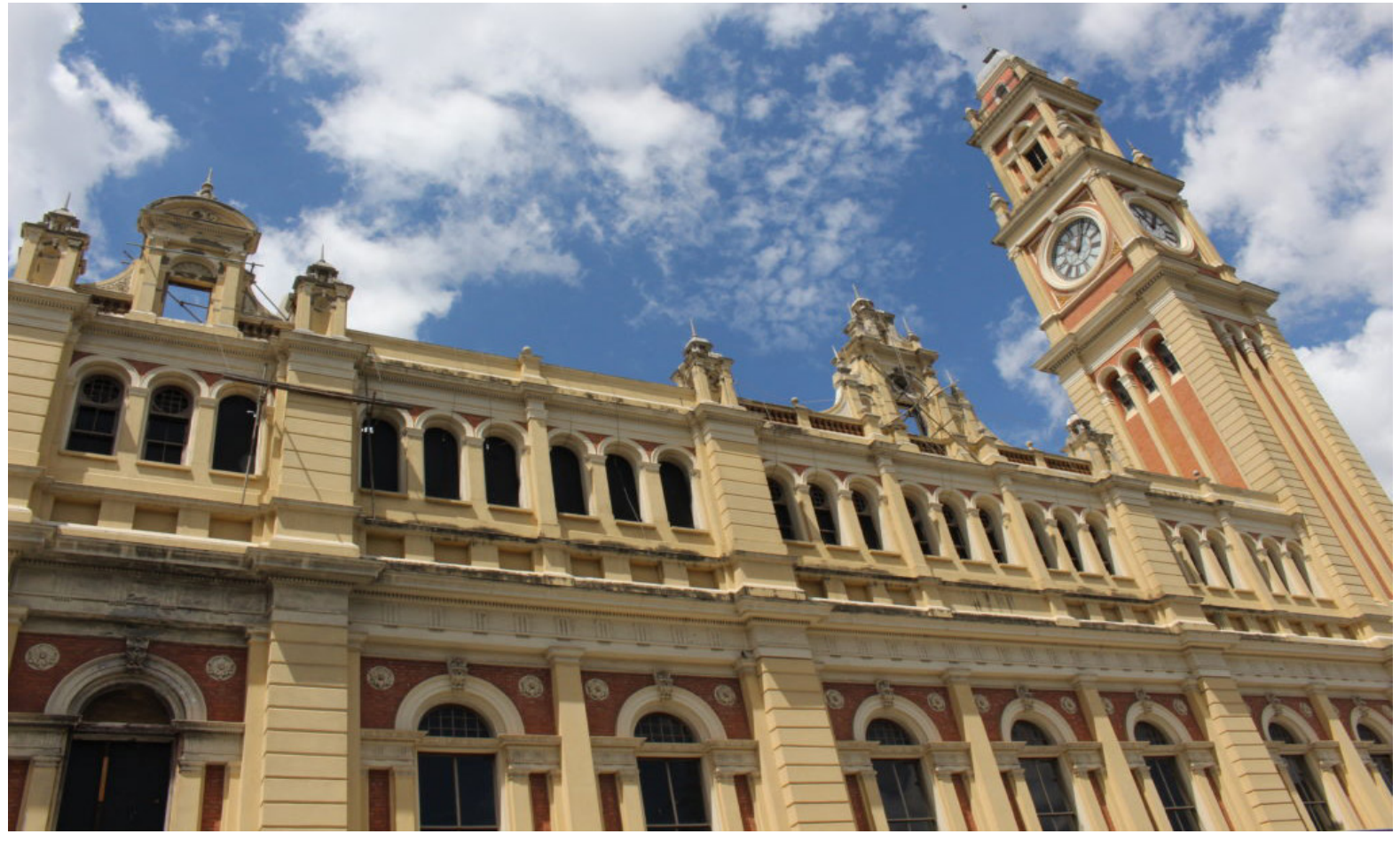

Figura 1. Estação da Luz, São Paulo / SP. Fonte: Acervo de Vanessa Kraml, 2016.

8. Informação STCR-159/76

assinada por Carlos Lemos,

13/08/1976, Processo n.

20.097/76, fl.85-86.
Nos tombamentos anteriores de bens ferroviários no estado de São Paulo, contudo, observamos a nítida predileção pelas estações consideradas isoladamente, associadas a "uma memória pitoresca e nostálgica das antigas paradas" (MARTINS et al, 2012, p. 55) e valorizadas, sobretudo, pela sua excepcionalidade arquitetônica ou construtiva. Em alguns tombamentos de bens ferroviários datados das décadas de 1980 e 1990, observamos a menção à dimensão urbana e territorial associada às estruturas ferroviárias, mas o foco da tutela recai sobre o edifício da estação considerado isoladamente, sugerindo uma leitura das relações urbanas a partir desse ponto referencial. Os argumentos e considerações elaborados em diversos pareceres, no entanto, apontam para uma gradativa expansão dessa percepção. Nos tombamentos da Estação da Luz e da Estação de Campinas, observamos a alusão ao conceito de "patrimônio ambiental urbano" como um dos principais argumentos para a preservação. No parecer do arquiteto Carlos Lemos são citadas três justificativas para o tombamento da Estação da Luz: a importância da estação como testemunho do ciclo café e do período de expansão da industrialização entre o final do século XIX e início do século XX; o papel da estação na leitura de nossa cidade, ou seja, sua importância na composição da paisagem e na inteligibilidade daquele espaço urbano, considerando-a "elemento referencial importante e partícipe inconteste do patrimônio ambiental urbano paulistano"8 e, finalmente, as técnicas empregadas e os méritos arquitetônicos do edifício (Figura 1).

O processo de tombamento da Estação de Campinas apresenta considerações semelhantes no que tange à questão urbana. Além do interesse histórico e arquitetônico, o parecer de abertura redigido por Murillo Marx atenta para a importância paisagística, para "a presença do conjunto como referencial marcante da cidade", aludindo para o evidente desenvolvimento urbano anunciado pela ferrovia, fazendo Campinas vislumbrar um "futuro metropolitano", e para a repercussão 


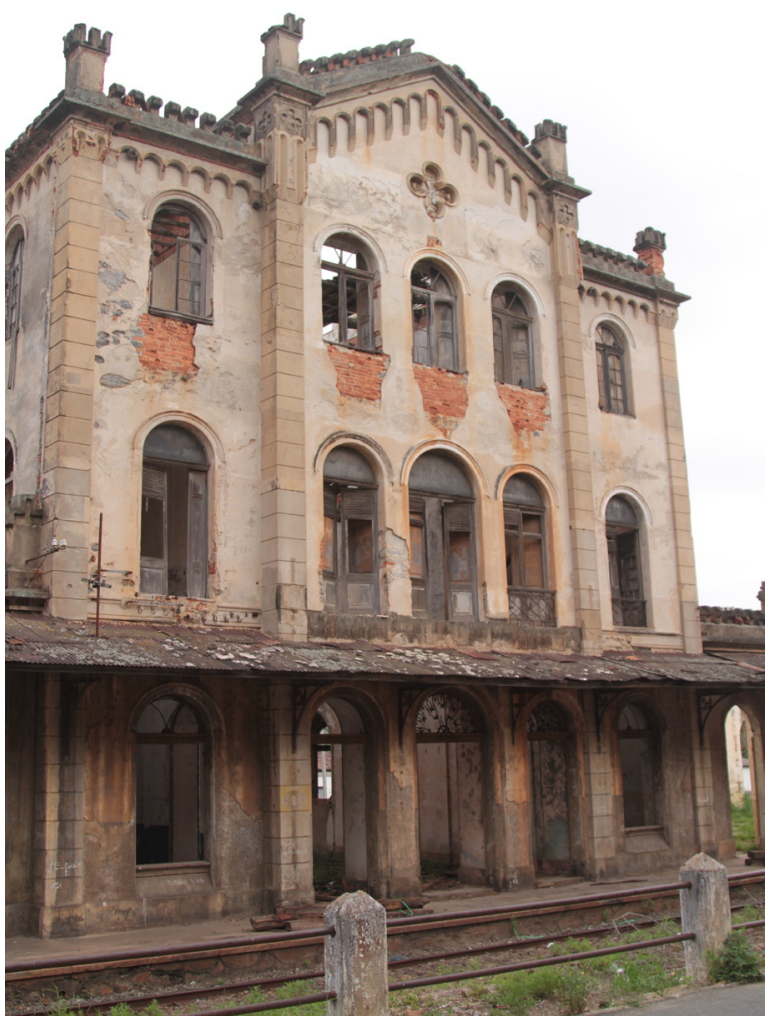

Figura 2. Estação de Cachoeira Paulista / SP. Fonte: Acervo de Indira Ferreira Faria, 2016.

9. Parecer assinado por Murillo Marx, sobre a abertura de Processo de Tombamento da Estação Ferroviária de Campinas, 20/11/1978, Processo n.20.682/78, fl.27. Grifos nossos.

10. Decisão do Conselho, 21/07/1980, Processo n. 20.682/78, fl.108. Grifo nosso. das estruturas ferroviárias nas práticas de ocupação territorial do Estado. Murillo Marx apresenta as seguintes justificativas para abertura do processo:

a) Interesse histórico indiscutível por testemunhar aquele parque ferroviário empreendido pelo capitalista pioneiro na implantação das estradas de ferro que subverteram a ocupação tradicional do território paulista;

b) Interesse arquitetônico atestável pelo porte e pelo esmero dum ecletismo precoce em nossas terras pelo seu romantismo já na volumetria pitoresca, já nos materiais e nas técnicas empregadas;

c) Interesse paisagístico notório para todo campineiro e forasteiro, dada a presença do conjunto como referencial marcante na cidade, que tanto tendo perdido no seu passado, avança célere para um futuro metropolitano ${ }^{9}$.

Na decisão final do Conselho, a estação foi tombada como "monumento de interesse histórico-arquitetônico, vinculado à criação das estradas de ferro, como fator de escoamento da produção cafeeira, em nosso Estado", atribuindo-se ao edifício, finalmente, a qualidade de "importante marco no patrimônio ambiental urbano"10. Em ambos os processos, das estações da Luz e de Campinas, observamos o emprego do mesmo conceito que carrega consigo a trajetória de discussões empreendidas pelo órgão naquele momento.
Também no processo de tombamento da Estação de Cachoeira Paulista observamos a referência à influência da ferrovia na composição de um "peculiar ambiente urbano", formado pela dinamização das atividades comerciais e pela afluência de trabalhadores, artistas e artífices que contribuíram sobremaneira para a configuração urbana local. O parecer de abertura do processo cita, nesse sentido, a contribuição do próprio engenheiro Newton Bennaton, autor do projeto da estação e de diversas residências na cidade, além da presença de mestres italianos, como Brás Império e João Vitelli, responsáveis pela construção de edifícios importantes, como o Teatro Municipal. Interessante ressaltar que tanto o parecer de abertura do processo como a decisão final do Conselho alicerçam suas argumentações justamente na importância da estação como testemunho do processo de ocupação e desenvolvimento do Vale do Paraíba, já que o conjunto das edificações ferroviárias fora considerado de pouco interesse artístico e arquitetônico ${ }^{11}$ (Figura 2).

Situação semelhante se observa no tombamento da Estação Barracão, na cidade de Ribeirão Preto. Argumentou-se que, não obstante as características arquitetônicas e construtivas similares às de outras estações da Companhia Mogiana, o edifício teria adquirido importância cultural para a comunidade, além de possuir particular localização em área urbanizada, representando teste- 
12. Parecer Técnico de Regina Pontim e Parecer do Conselheiro Eduardo Corona, Processo n. 21.364/80, fls. $7-9,27$

13. Neste artigo, não aprofundaremos a análise do tombamento do Complexo Ferroviário de Paranapiacaba, na cidade de Santo André, devido à complexidade das questões envolvidas, que escapam ao nosso escopo.

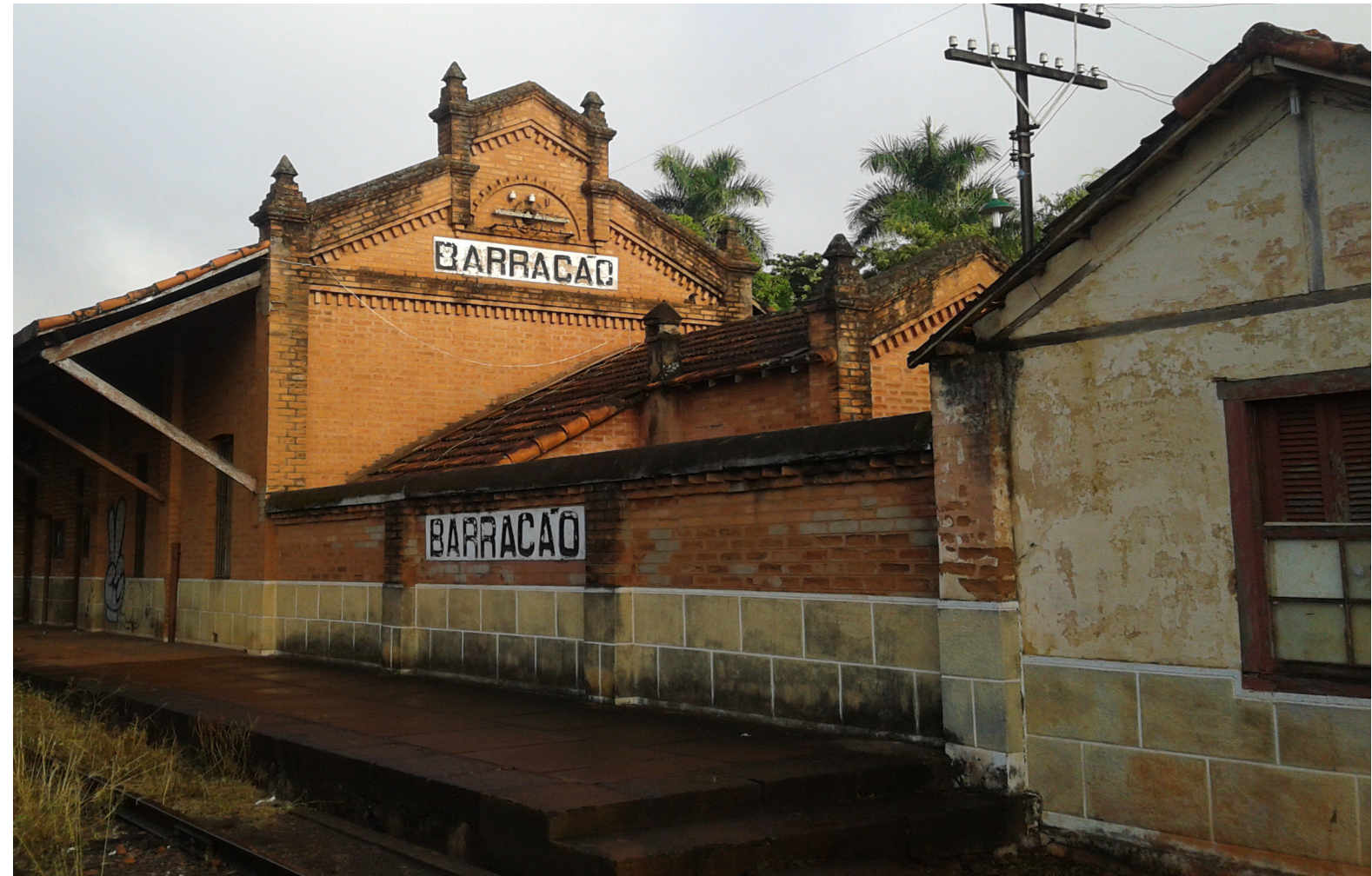

Figura 3. Estação Barracão, Ribeirão Preto / SP. Fonte: Acervo de Luis Gustavo Pereira Ferreira, 2012

munho importante para a história urbana e social local (Figura 3) ${ }^{12}$.

Essas questões pouco a pouco foram incorporadas aos argumentos e justificativas de tombamento, acompanhando o aumento da participação da sociedade civil na abertura de processos e em movimentos de defesa desses bens. $\mathrm{O}$ tombamento do Complexo Ferroviário de Paranapiacaba, datado de 1987, apontou nessa direção. O pedido de tombamento foi impulsionado por movimentos populares em defesa do patrimônio local, reunindo associações e representantes de órgãos públicos preocupados com a crescente degradação da vila e do entorno ${ }^{13}$. A proteção legal incidiu sobre todo um perímetro construído, incluindo edifícios e outros bens ferroviários, considerados em sua relação com o meio natural e antrópico. Foram tombados a "Vila Ferroviária, a Parte Alta, ferrovia e acervo, paisagem envoltória representativa do conjunto serrano da Serra do Mar, onde se encontram as bacias de drena- 
gem formadoras do Rio Mogi e Rio Grande da Serra ou Jurubatuba, além das cabeceiras que abastecem o núcleo urbano"14.

Ainda com relação aos bens ferroviários, cumpre salientar a preocupação de Carlos Lemos com a necessidade de estudá-los e valorá-los como parte de um conjunto mais amplo, atentando para a perda de significados dos edifícios tombados de forma isolada. Não obstante a referência imediata aos critérios de preservação pautados pelos ciclos econômicos evidenciados pela historiografia em voga - ou, ainda, pela excepcionalidade arquitetônica, práticas correntes nas ações preservacionistas do período -, a preocupação de Lemos indica a percepção de uma estreita correlação entre bens ferroviários e desenhos territoriais, elemento de suma importância para a compreensão do patrimônio industrial. O tema é citado em alguns processos, como no caso das estações da Luz, de Santa Rita do Passa Quatro e de Campinas, sinalizando a efervescência de um debate que tomava corpo nas discussões internas do órgão, no final da década de 1970. Em parecer relacionado ao tombamento da Estação da Luz, Lemos enfatiza a necessidade de estudá-la em conjunto com outros bens vinculados ao café, observando todo um contexto destinado ao transporte, estocagem, comercialização e exportação ${ }^{15}$. A questão, no entanto, já vinha sendo discutida no seio do órgão, como podemos notar no processo de tombamento da Estação de Santa Rita do Passa Quatro:
Mais uma vez, no entanto, encarecemos a necessidade de um plano de tombamentos que nos oriente no sentido do que tombar $e$ do que não tombar dentro do Estado. [...] Se uma das normas for o tombamento de bens culturais alusivos aos vários ciclos econômicos - em relação ao café, por exemplo -, deveremos tombar tudo aquilo que a ele tenha ligação e aí estaria justificada a inclusão das estradas de ferro que levavam o ouro verde à Santos. E desde já se percebe que uma estação sozinha, já sem os seus trilhos e comboios, não exprime nada a não ser se possua condições excepcionais de interesse arquitetônico, como é o caso, por exemplo, da estação de Mayrinque, projeto de Dubugras $^{16}$.

Anos depois, a questão é novamente enfatizada no processo de tombamento da Estação de Campinas:

Realmente, trata-se de construção eclética que vem mesmo simbolizar a arquitetura do café do século $X X$, e que julgamos digna de tombamento. No entanto, ainda repetimos, achamos justo um critério de tombamento que venha arrolar também outras estações e outras obras ferroviárias, tanto armazéns como pontes ou viadutos, que, em conjunto, representem todo o esforço de escoamento do café até o porto de Santos ${ }^{17}$.

Ainda que, naquele momento, essas questões não tenham sido efetivamente incorporadas às resoluções de tombamento (geralmente centradas em edifícios isolados, como as estações), com base nos exemplos citados observamos los Lemos, 06/06/1979, Processo no. 20.682/78, fl.50. Grifo nosso. 
18. Para aprofundamentos sobre as políticas de preservação do patrimônio ferroviário em âmbito estadual, ver: OLIVEIRA, 2010, p.179203; OLIVEIRA e MORAES, 2017, p.18-42.

19. Pareceres de Ulpiano Bezerra de Meneses e José Pedro de Oliveira Costa, Processo n.22.261/82.

20. Processo n. 31877/94; Res. SC-61, de 30/10/2007, D.O.E. de 28/12/2007, p.40.

21. Processo n. 26030/88; Res. SC-46, de 18/12/1992, D.O.E. de 19/12/1992, pg. 25.

22. Processo n. 46.662/03; Res. SC-20, de 26.03.2010, D.O.E. de 12/05/2010, p.35.

23. Res. 7 , de 04/03/1985 D.O.E. de 05/05/1985, p.9.

24. Pareceres de Silvia Ferreira Santos Wolff, Marly Rodrigues e José de Souza Martins, Processo n.26.399/88.

25. Res. SC-128, de 19/12/2016, D.O.E. de 21/12/2016, p. 55.

26. Res. SC-13, de 26/02/2018, D.O.E. de 27/02/2018, p. 32-33.

27. Processo n. 39684/00; Res. SC-52, de 01.10.2007, D.O.E. de 04/10/2007, p.52. que as dificuldades relativas à preservação do patrimônio ferroviário em sua dimensão urbana e territorial já eram tema de debate desde meados da década de $1970^{18}$

Abordando a questão para além do universo ferroviário, notamos que o tema da dimensão urbana também comparece em processos de tombamento de edifícios e sítios de outras tipologias industriais. No processo de tombamento do conjunto arquitetônico da Kaigai Kogyo Kabushiki Kaisha, conhecido como KKKK, foi ressaltada a importância do empreendimento para o desenvolvimento urbano da cidade de Registro como um dos principais argumentos para sua preservação. Os galpões voltados ao beneficiamento de arroz foram implantados às margens do rio Ribeira em meados da década de 1920, em área pouco urbanizada, nas proximidades do porto fluvial. Devido ao caráter de entreposto cooperativo, a atividade não chegou a atrair um grande número de trabalhadores, mas o funcionamento da atividade fabril permitiu o incremento das funções urbanas e o desenvolvimento da cidade, fato destacado ao longo do processo de tombamento ${ }^{19}$.

A importância do conjunto fabril na conformação da paisagem urbana comparece em vários processos, a exemplo da Cia. Fiação e Tecelagem São Martinho, considerado um conjunto arquitetônico definidor da identidade histórica, cultural e urbana de Tatuí20; das Indústrias Reunidas Francisco Matarazzo, na cidade de Marília, enfa- tizando a grande extensão do conjunto industrial e sua representatividade na conformação urbana local21; do Complexo Industrial do Gasômetro e Casa das Retortas, conjunto alusivo ao processo de modernização da cidade de São Paulo e marco referencial na paisagem do bairro do Brás ${ }^{22}$; do antigo Matadouro de Vila Mariana, construção pioneira no bairro e "agente catalisador do desenvolvimento urbano da região"23; e do Mercado Municipal Paulistano, citado como uma das grandes obras realizadas entre o final da década de 1920 e início da década de 1930 e que teria transformado a fisionomia da cidade, ao lado do Edifício Martinelli e da retificação do Rio Tamanduateí ${ }^{24}$. Argumentos semelhantes também se observam em processos mais recentes, como o tombamento de Edifícios da Antiga Fábrica da Companhia Gessy Industrial, em Valinhos, datado de 2016, que considerou, entre outros valores, o "relevante papel" do conjunto industrial "como referencial espacial na conformação da paisagem da cidade"25; e o tombamento do Edifício do Moinho Fratelli Maciotta, em Ribeirão Pires, datado de 2018, que ressalta a relevante paisagem industrial formada pela relação entre o edifício e a ferrovia ${ }^{26}$.

Além da representatividade na paisagem, outro aspecto evidenciado foi a participação dos capitais da indústria na expansão urbana, fato citado no processo da Cervejaria Paulista, em Ribeirão Preto (Figura 4) ${ }^{27}$. Ocupando extensos terrenos urbanos, a fabricação de cerveja repercutiu na 


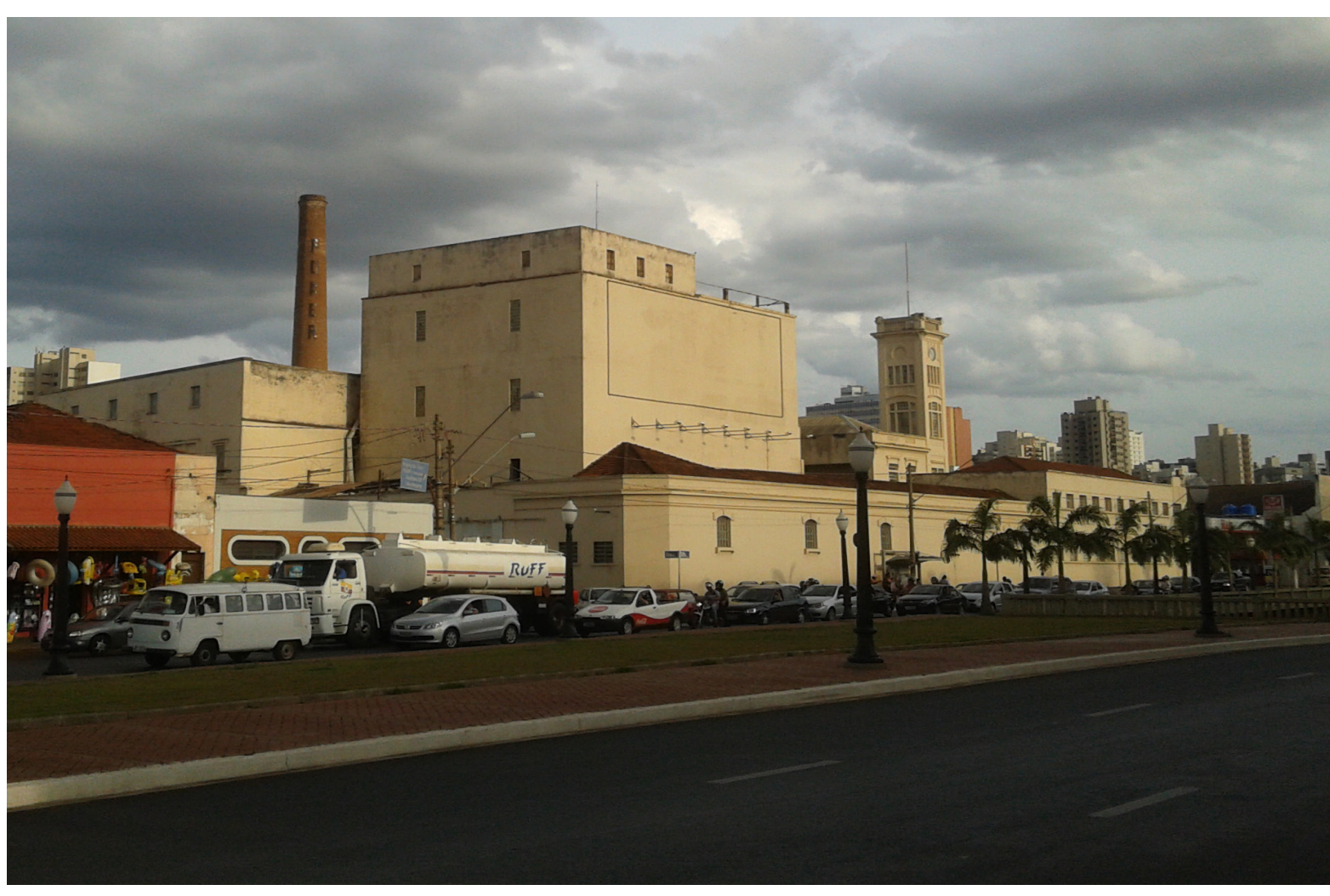

Figura 4. Cervejaria Paulista, Ribeirão Preto / SP. Fonte: Acervo de Luis Gustavo Pereira Ferreira, 2012.

28. Processo n. $29840 / 92$. Res. 26 de 15/12/1993, D.O.E. de 16.12.1993, p.53.

29. Pareceres de Marly Rodrigues em junho de 1997 e em outubro de 2005, Processo n. $28.682 / 91$.

30. Res. SC-021, de 09-052013, D.O.E. de 22/05/2013 p.68-69. configuração urbana local não somente devido à grande extensão de suas instalações, mas também graças aos investimentos imobiliários promovidos pelos proprietários da Cervejaria Paulista, sobretudo na Praça XV de Novembro, como a reabilitação de um antigo hotel e a construção do Teatro Pedro II e do edifício Meira Júnior; imóveis que hoje compõem o Quarteirão Paulista, conjunto eclético tombado pelo CONDEPHAAT em $1993^{28}$.
No caso da Estação de Bondes do Brás, na cidade de São Paulo, tombada em 2008, além de observarmos o destaque à dimensão urbana do conjunto - aludindo à importância do bonde como sistema de transporte e como símbolo da modernização, elemento que permitirá a incorporação de novas perspectivas de sociabilidade e de convivência urbana -, notamos ao longo do processo a intenção de ir além da mera evidenciação textual, sugerindo um encaminhamento prático que viabilizasse essa leitura. Nesse sentido, cogitou-se a possibilidade de unir o estudo da estação de bondes a um conjunto maior de bens no mesmo bairro, com o intuito de impulsionar novas leituras do acervo arquitetônico do Brás e evitar a recorrência aos tombamentos de imóveis isolados. Ainda que esse caminho não tenha sido adotado, o parecer relatou o problema da acelerada degradação do entorno e sugeriu que as medidas de proteção da estação caminhassem no sentido de orientar a leitura desse contexto ${ }^{29}$.

Nos processos dos anos 2010, como no caso do Complexo Industrial Carioba, em Americana, datado de 2013, os argumentos expostos na resolução de tombamento atentam para a valorização de um conjunto de edifícios que "sintetiza a vida industrial através dos equipamentos que ali foram construídos"30. Logo, o tombamento buscou abarcar o complexo fabril a partir de uma compreensão mais ampla de sua funcionalidade e relação com a dinâmica urbana envoltória-assim como observamos no tratamento 
dos bens ferroviários pelo CONDEPHAAT, nesse mesmo período -, incorporando ao perímetro de tombamento tanto os equipamentos diretamente relacionados à produção industrial, a exemplo dos galpões de tecelagem e da usina para fornecimento de energia, como também o grupo escolar, igreja, edifícios voltados ao lazer e ao atendimento de saúde dos operários e residências vinculadas ao núcleo fabril. Seguindo diretriz semelhante, a caracterização como "último remanescente têxtil-industrial que mantém leitura de conjunto em Jundiaí" foi um dos motivos elencados para a preservação do complexo construído, na resolução de tombamento dos Edifícios da Argos Industrial, sua Creche e Vila Operária, cuja publicação data de $2017^{31}$. Foram tombados os edifícios da fiação, confecção, oficinas mecânicas, estoque de algodão, armazém, filtro, portaria e chaminé; além da creche e da Vila Argos, constituída pelas Casas de Funcionários. A resolução acrescenta, ainda, como motivação para a tutela do conjunto, o fato de que "as relações trabalhistas transcenderam - ambiente fabril, impactando nas relações sociais dos trabalhadores", considerando que os edifícios elencados "são importantes para a perpetuação da memória operária industrial [e] de fundamental relevância para a compreensão da História paulista", afirmação em consonância com a definição de patrimônio industrial emanada dos Princípios de Dublin, conforme acenamos.

31. Res. SC-065, de 19/12/2017, D.O.E. de 22/12/2017, p. 57-58. múltiplas dimensões do patrimônio industrial, sabemos que os mecanismos de tutela disponíveis ainda não permitem a efetiva fruição dessas especificidades e valores após a incidência da proteção legal. Como instrumento jurídico, o tombamento limita-se à tutela material de edifícios ou conjuntos construídos. Contudo, adequando as análises do estudioso italiano Gaetano Miarelli Mariani para a realidade brasileira, notamos que a preservação desses bens cujos valores patrimoniais extrapolam a dimensão do edifício e invadem a cidade e o território, abarcando funções, usos e sociabilidades, carece de metodologias de análise e de instrumentos práticos de tutela que alcancem além dos aspectos externos, visíveis e materiais. Encontramo-nos, na realidade, diante de bens culturais, "resultados de atividades práticas que tendem a realizar uma arte de viver, uma arte de fabricar e que, justamente no cumprimento de tais fins, dão vida à formas, e por conseguinte também a valores estéticos" (MIARELLI MARIANI, 1993). Esse patrimônio, portanto, deve ser apreendido, valorizado e tutelado não somente, ou prioritariamente, com base em valores formais, e sim com base em sua importância testemunhal e em seu papel na composição de uma estrutura que não é apenas física, mas, sobretudo, memorial e sociocultural.

Para garantirmos a fruição desses valores na preservação do patrimônio da industrialização, portanto, outras medidas de proteção, complementares ao tombamento, precisariam ser construídas e
Nesta breve explanação, apesar de observarmos em diversos pareceres a paulatina apreensão das 
difundidas, contanto com a participação da sociedade civil e das demais esferas da administração pública, em nível estadual e em cada município, de modo a promover ações articuladas àquelas propostas pelos órgãos de preservação. $A$ inserção da problemática da preservação em planos urbanísticos geridos pelas municipalidades, a elaboração de levantamentos na escala urbana e territorial, o fomento à educação patrimonial na escala do município e o desenvolvimento de programas de apoio à gestão dos bens tombados, acompanhando sua transformação ao longo do tempo e oferecendo incentivos fiscais e operacionais para que a coletividade possa participar ativamente da manutenção e dinamização dos patrimônios de cada cidade, são alguns caminhos possíveis e potencialmente promissores; há muito debatidos na literatura preservacionista, porém ainda distantes da prática efetiva.

\section{Referências Bibliográficas}

CURY, Isabelle. (Org.) Cartas Patrimoniais. $2^{\mathrm{a}}$. ed. Rio de Janeiro: IPHAN, 2000.

ICOMOS, TICCIH. Princípios conjuntos do ICOMOS-TICCIH para a Conservação de Sítios, Estruturas, Áreas e Paisagens de Património Industrial. [Princípios de Dublin]. Aprovados na 17. ${ }^{\text {a }}$ Assembleia Geral do ICOMOS, em 28 de Novembro de 2011.
MARTINS, Ana Luiza; CARDOSO, Jordana e ANDRADE, Marcelle Marques de. Notas sobre a preservação do patrimônio ferroviário de São Paulo. In: PAULA, Z. C. et al. (Orgs.). Polifonia do patrimônio. Londrina: EDUEL, 2012.

MENEGUELLO, Cristina. Patrimônio industrial: memórias, acervos e cidade. In: PAULA, Z. C. et al. (Orgs.). Polifonia do patrimônio. Londrina: EDUEL, 2012.

MIARELLI MARIANI, Gaetano. Restauro e Territorio: Appunti su un Rapporto Difficile e Controverso [1978]. In: Centri Storici: note sul tema. Roma: Bonsignori, 1993.

MENESES, Ulpiano Bezerra de. Patrimônio, Preservação e História da Energia. In: Anais do $1^{\circ}$ Seminário Nacional de História e Energia. São Paulo: Departamento de Patrimônio Histórico, 1988.

OLIVEIRA, Eduardo Romero de. Patrimônio ferroviário do Estado de São Paulo: as condições de preservação e uso dos bens culturais. Revista Projeto História, v.40 (2010), p.179-203.

OLIVEIRA, Eduardo Romero de; Ewerton Henrique. O patrimônio ferroviário nos tombamentos no Estado de São Paulo. Revista Memória em Rede, v.9, n.16, Jan./Jul.2017 p.18-42. 
PARISELLA, Antonio. II futuro del passato industriale. Roma Moderna e Contemporanea, anno VIII, n.1-2, 2000.

RODRIGUES, Marly. Imagens do Passado. São Paulo: Ed. Unesp, 2000.

RODRIGUES, Marly; TOURINHO, Andrea de Oliveira. Patrimônio ambiental urbano: uma retomada. Revista CPC, São Paulo, n.22, p.70-91, jul./ dez. 2016, p.70-91.

RUFINONI, Manoela. Preservação e Restauro Urbano: intervenções em sítios históricos industriais. São Paulo: Ed. Fap-Unifesp, Edusp, Fapesp, 2013.

SÃO PAULO (Estado). Lei Estadual 10.247 de 22 de outubro de 1968. Dispõe sobre a competência, organização e o funcionamento do ConseIho de Defesa do Patrimônio Histórico, Artístico e Turístico do Estado, criado pelo artigo 123 da Constituição Estadual e dá outras providências.

TICCIH. Carta de Niznhy Tagil sobre o patrimônio industrial. Niznhy Tagil: The International Committee for the Conservation of the Industrial Heritage, 2003.

\section{Processos de Tombamento}

SÃO PAULO (Estado). Secretaria de Estado da Cultura. Conselho de Defesa do Patrimônio Histórico, Arqueológico, Artístico e Turístico. Processo CONDEPHAAT no. 00467/74. Estação de Santa Rita do Passa Quatro.

Processo CONDEPHAAT no.

20097/76. Estação da Luz (São Paulo).

Processo CONDEPHAAT no.

20316/77. Estação Ferroviária de Cachoeira Paulista (Cachoeira Paulista).

Processo CONDEPHAAT no. 20682/78. Estação Ferroviária de Campinas (Campinas).

Processo CONDEPHAAT no.

21364/80. Estação Barracão (Ribeirão Preto).

\section{Processo CONDEPHAAT no}

22209/82. Complexo Ferroviário de Paranapiacaba (Santo André).

Processo CONDEPHAAT no. 22261/82. Conjunto Arquitetônico da Kaigai Kogyo Kabushiki Kaisha (Registro)

. Processo CONDEPHAAT no. 26399/88. Mercado Municipal de São Paulo (São Paulo)

Processo CONDEPHAAT no. 26030/88. Indústrias Reunidas Francisco Matarazzo (Marília). 
Processo CONDEPHAAT no. 28682/91. Res. SC-37, de 30/09/1987. D.O.E. de

Estação de Bondes do Brás (São Paulo). 03/10/1987, p.18.

Processo CONDEPHAAT. no Res. SC-46, de 18/12/1992, D.O.E. de 29840/92. Quarteirão Paulista e Praça XV de Novembro (Ribeirão Preto). 19/12/1992, pg. 25 .

Res. 26 de 15/12/1993, D.O.E. de 16/12/1993, p.53.

Processo CONDEPHAAT no.

Res. SC-61, de 30/10/2007, D.O.E. de 28/12/2007, p.40.

Processo CONDEPHAAT no. Res. SC-52, de 01/10/2007. D.O.E. de 39684/00. Cervejaria Paulista. (Ribeirão Preto).

46662/03. Complexo do Gasômetro e Casa das 04/10/2007, p.32.

Retortas (São Paulo).

Res. SC-20, de 26.03.2010, D.O.E. de 12/05/2010, p.35.

Res. SC-021, de 09-05-2013. D.O.E. de 22/05/2013, p. 68-69.

Res. SC-128, de 19/12/2016, D.O.E. de 21/12/2016, p. 55.

\section{Resoluções de Tombamento}

Res. SC-065, de 19/12/2017, D.O.E. de

Res.SC-22, de 03/05/1982, D.O.E. de 07/05/1982.

22/12/2017, p. $57-58$

Res. 7, de 04/03/1985, D.O.E. de 05/05/1985, p.9.

Res. SC-13, de
$27 / 02 / 2018$, p. $32-33$. 